\title{
Discovery and Validation of Novel Protein Markers in Mucosa of Portal Hypertensive Gastropathy
}

\section{Ying Zhu}

Southern Medical University Shenzhen Hospital

Wen Xu

Southern Medical University Shenzhen Hospital

Wei Hu

Southern Medical University Shenzhen Hospital

\section{Fang Wang}

Southern Medical University Shenzhen Hospital

Yan Zhou

Bethune International Peace Hospital

Jianguo Xu ( $\nabla$ xujianguo1@smu.edu.cn )

Southern Medical University Shenzhen Hospital

Wei Gong

Southern Medical University Shenzhen Hospital

\section{Research Article}

Keywords: Biomarker, Label-free quantitative mass spectrometry, Liver cirrhosis, Parallel reaction monitoring, Portal hypertension gastropathy, Proteomics

Posted Date: February 11th, 2021

DOI: https://doi.org/10.21203/rs.3.rs-184251/v1

License: @) (7) This work is licensed under a Creative Commons Attribution 4.0 International License. Read Full License 


\section{Abstract}

Background: Portal hypertension induced esophageal and gastric varix bleeding is the main cause of death among patients of decompensated liver cirrhosis. Therefore, a standardized, biomarker-based test, to make an early-stage non-invasive risk assessment of portal hypertension, is highly desirable. However, no fit-for-purpose biomarkers have yet been identified.

Methods: We conducted a pilot study consisting of 5 portal hypertensive gastropathy (PHG) patients and 5 normal controls, sampling the gastric mucosa of normal controls and PHG patients before and after endoscopic cyanoacrylate injection, using label-free quantitative (LFQ) mass spectrometry, to identify potential biomarker candidates in gastric mucosa from PHG patients and normal controls. Then we further used parallel reaction monitoring (PRM) to verify the abundance of the targeted protein.

Results: LFQ analyses identified 423 significantly differentially expressed proteins. 17 protein that significantly elevated in the gastric mucosa of PHG patients were further validated using PRM.

Conclusions: This is the first application of an LFQ-PRM workflow to identify and validate PHG-specific biomarkers in patient gastric mucosa samples. Our findings lay the foundation for comprehending the molecular mechanisms of PHG pathogenesis, and provide potential applications for useful biomarkers in early diagnosis and treatment.

Trial Registration: Trial registration was completed (ChiCTR2000029840) on February 25, 2020.

\section{Background}

Liver cirrhosis is the end stage of chronic liver disease characterized by fibrosis and structurally abnormal nodules. Decompensation stage cirrhosis manifests as hepatic dysfunction and portal hypertension (PH)(1). The PH-induced esophagogastric variceal bleeding (EGVB) was the main cause of death in patients with cirrhosis(1). Therefore, it is of great significance to understand the pathogenesis and clinical manifestations of EGVB and develop effective prevention and treatment strategies accordingly to reduce the occurrence of EGVB and its related mortality.

According to Portal Hypertensive Bleeding in Cirrhosis: Risk Stratification, Diagnosis, and Management: 2016 Practice Guidance by the American Association for the Study of Liver Diseases(2), platelet count, ultrasound, transient elastograph (TE), computed tomography (CT), or magnetic resonance imaging (MRI) are suggested as non-invasive methods to evaluate the severity of cirrhosis and $\mathrm{PH}$. It also proposed that patients with compensated cirrhosis with liver stiffness $<20 \mathrm{kPa}$ (determined by TE) and a platelet count $>150,000 / \mathrm{mm}^{3}$ were very unlikely to have high-risk varices $(<5 \%)$, and endoscopy could be safely avoided in them(3). Patients with cirrhosis who do not meet the above criteria should undergo endoscopic examination to assess the presence of varicose veins. However, the imaging examination methods mentioned above have higher requirements on operating physicians and are subjective and restrictive to a certain extent. Currently, there is still a lack of non-invasive indicators for $\mathrm{PH}$ severity and objective quantitative assessment. Accordingly, there remains a clinical need for new biomarkers that achieve quantified, inexpensive, and minimally invasive testing to assess the severity of $\mathrm{PH}$.

For patients with gastroesophageal varices (GOV) or EGVB, endoscopic cyanoacrylate injection eradicates varices with assistance of preoperative portal vein CT angiography and endoscopic ultrasound. However, our follow-up after 1 week of operation found that portal hypertensive gastropathy $(\mathrm{PHG})$ became more severe, presenting as exacerbation of redness, point bleeding or a fine reticular pattern separating areas of raised edematous mucosa, the "mosaic pattern", which may attributes to the development of gastric capillary ectasia and collateral veins after obstruction of the esophageal varices(4). Gastroscopy can provide an accurate PHG diagnosis and classification $(4,5)$. Therefore, we sampled the gastric mucosa of the patients with compensated cirrhosis before and after endoscopic cyanoacrylate injection, and attempted to discover differentially expressed proteins (DEPs) which may appropriate for non-invasive diagnosis of $\mathrm{PH}$ severity.

Several studies have sought to determine disease biomarkers in gastric mucosa, with a view to the development of clinically relevant risk stratification and diagnostic tests $(6,7)$. However, these studies didn't provide sufficient resolution to differentiate 
the stage of PHG. The need to develop new and more effective non-invasive tests is therefore still obvious. Here, we report a pilot study applying label-free quantitative (LFQ) mass spectrometry to discover potential biomarker candidates, followed by targeted parallel reaction monitoring (PRM) to verify the PHG-related protein changes between decompensated liver cirrhosis patients and normal controls. This is the first use of LFQ-PRM for PHG biomarker discovery, and establishes the methodology required for subsequent studies to evaluate specific disease biomarkers of decompensated liver cirrhosis.

\section{Results}

\subsection{Clinical sample information}

In this study, we evaluated the application of label-free mass spectrometry and PRM to identify and validate promising biomarkers for assessing the severity of $\mathrm{PH}$ in decompensated liver cirrhosis patients. The overall strategy and simplified technology roadmap are shown in Fig. 1. In total, 15 gastric mucosa samples ( $=5$ Nor group, $n=5 \mathrm{Ph}$ group, $n=5$ Inter group) were collected from individual patients for this study. The baseline characteristics of each group are presented in Table 1. Compared with healthy volunteers, the gastric mucosa of liver cirrhosis patients presents reddening, edematous, or even point bleeding and the appearance of the gastric mucosa after endoscopic cyanoacrylate injection were more severe (Fig. 2). To provide consistency at point-of-collection, gastric mucosa samples were collected immediately during gastroscopy and processed identically.

Table 1

Baseline characteristics of PHG patients compared with controls.

\begin{tabular}{|c|c|c|c|c|}
\hline & Nor & $\mathrm{Ph}$ & Inter & $p$ value \\
\hline Male gender & $5(55.6 \%)$ & $7(70 \%)$ & $7(70 \%)$ & 0.370 \\
\hline Age (years) & $39.2 \pm 3.32$ & $45.8 \pm 2.88$ & $45.8 \pm 2.28$ & 0.187 \\
\hline Classification of PHG & 0 & $1.4 \pm 0.11$ & $2.4 \pm 0.09$ & $<0.05$ \\
\hline Child-pugh score & 5 & $8.1 \pm 0.24$ & $6.4 \pm 0.15$ & $<0.05$ \\
\hline Liver stiffness(kPa) & $2.12 \pm 0.16$ & $32.34 \pm 0.67$ & $32.16 \pm 0.67$ & $<0.05$ \\
\hline Platelet count $\left(\mathrm{mm}^{3}\right)$ & $213.3 \pm 12.7$ & $62.5 \pm 2.46$ & $88.4 \pm 4.39$ & $<0.05$ \\
\hline Portal vein diameter $(\mathrm{mm})$ & $3.87 \pm 1.02$ & $15.9 \pm 0.72$ & $15.9 \pm 0.72$ & $<0.05$ \\
\hline \multicolumn{5}{|c|}{$\begin{array}{l}\text { Values reported as mean } \pm \text { SEM. Classification of PHG: Grade } 0 \text { : no PHG. Grade } 1 \text { : mild reddening, mucosa was congestive } \\
\text { but there was no mosaic pattern. Grade 2: severe redness and a fine reticular pattern separating areas of raised edematous } \\
\text { mucosa, the "mosaic pattern," or a fine red speckling were present. Grade 3: Point bleeding was recognized in the state of } \\
\text { grade 2. }\end{array}$} \\
\hline
\end{tabular}

\subsection{Identification of DEPs by LS-MS/MS Analysis}

Using the LFQ workflow we identified a total of 6443 proteins (57277 peptides) in the discovery cohort samples, with quantified a total of 5595 proteins. We utilized the quantitative ratio value of relative expression of protein and the corresponding T-test $\mathrm{P}$ value to screen the DEPs of normal controls and PHG patients before or after operation. A total of 423 proteins were found to be significantly differentially expressed under the selection criteria, of which 226 between Inter. group and Nor. group (113 up-regulated and 113 down-regulated), 19 between Inter. group and Ph. group (4 up-regulated and 15 down-regulated), 178 were found between Ph. group and Nor. group (83 up-regulated and 95 down-regulated) (Fig. 3A). Out of 423 DEPs, 101 DEPs were found intersected among three group by comparison, which is shown by Venn diagram (Fig. 3B). The volcano plots based on the 423 DEPs are shown in Fig. 3C. All up-regulated and down-regulated DEPs are presented by heatmap, and their cluster analysis are performed (Fig. 4). 


\subsection{Bioinformatics analysis of differentially expressed proteins}

Gene Ontology (GO) level 2 analysis was performed to explain relevant biological processes (BP), molecular functions (MF), and cellular components (CC) of these differentially express proteins (Fig. 5A).

In the Inter/Nor comparison, the top three biological processes associated with the 226 DEPs were: cellular process (187 proteins), biological regulation (154 proteins) and metabolic process (117 proteins). The most relevant cellular component was the cell (197 proteins), followed by organelle (162 proteins), and membrane (107 proteins). For the top three molecular functions, $\mathrm{GO}$ terms relating to binding (141 proteins) were the most highly represented, followed by catalytic activity (68 proteins), and molecular function regulator (26 proteins).

In the Inter /Ph comparison, the top three biological processes associated with the 19 DEPs were: cellular process (15 proteins), cellular component organization or biogenesis (10 proteins), and biological regulation (10 proteins). The most relevant cellular component was the cell (16 proteins), followed by organelle (14 proteins), and membrane ( 9 proteins). For the top three molecular functions, GO terms relating to binding (10 proteins) were the most highly represented, followed by catalytic activity (5 proteins), and molecular function regulator (2 proteins).

In the $\mathrm{Ph} /$ Nor comparison, the top three biological processes associated with the 178 DEPs were: cellular process (129 proteins), biological regulation (120 proteins), and response to stimulus (94 proteins). The most relevant cellular component was the cell (146 proteins), followed by organelle (117 proteins), and membrane (79 proteins). For the top three molecular functions, GO terms relating to binding (99 proteins) were the most highly represented, followed by catalytic activity (50 proteins), and molecular function regulator (24 proteins).

To further determine the location of DEPs, subcellular location analysis was performed (Fig. 5B). The top three subcellular locations in Inter /Nor groups were extracellular (75 proteins, 33.19\%), nucleus (47 proteins, 20.8\%) and cytoplasm (40 proteins, $17.7 \%$ ). The top three subcellular locations in Inter/Ph groups were mitochondria (5 proteins, $26.32 \%$ ), nucleus (5 proteins, $26.32 \%$ ) and cytoplasm (4 proteins, $21.05 \%$ ). The top three subcellular locations in $\mathrm{Ph} /$ Nor groups were extracellular (69 proteins, $38.76 \%$ ), nucleus (32 proteins, $17.98 \%$ ) and cytoplasm (24 proteins, $13.48 \%$ ).

\subsection{Pathway enrichment analysis of differentially expressed proteins}

Kyoto Encyclopedia of Genes and Genomes (KEGG) database was used as annotations for protein metabolic pathways. As it's shown in Fig. 6, the gastric mucosa proteins up-regulated in PHG were involved in several pathways. In Ph/Nor comparison, hypertrophic cardiomyopathy (map 05410), vascular smooth muscle contraction (map04270) and cardiac muscle contraction (map04260) were the top 3 enriched pathways. In Inter /Nor comparison, focal adhesion (map04510), protein digestion and absorption (map 04974), and extracellular matrix (ECM)-receptor interaction (map04512) were the top 3 enriched pathways. It's worth noting that focal adhesion (map04510) and vascular smooth muscle contraction (map04270) were both enriched in $\mathrm{Ph} /$ Nor groups $(p=0.03, p=0.0001989$, respectively $)$ and Inter/Nor groups $\left(p=1.50 \times 10^{-6}, p=0.01\right.$, respectively). However, no pathway was enriched in Inter/Ph groups.

\subsection{Protein interaction analysis (PPI)}

We used the STRING database to build a regulatory network from DEPs participated in focal adhesion and vascular smooth contraction pathway in Inter/Nor group and Ph/Nor group to visualize the predicted interactions between DEPs in PHG (Fig. 7). In Inter/Nor group, the DEPs involved in focal adhesion include COL6A1, COL6A2, COL6A3, CAV2, TNC, ITGA1, MYLK, VWF, ACTN1, FLNA and FLNC. The DEPs involved in vascular smooth contraction include MYLK, ACTA2, ACTG2 and CALD1. In $\mathrm{Ph}$ /Nor group, the DEPs involved in focal adhesion include PDGFRB, TNC, CAV2 and ITGA1. The DEPs involved in vascular smooth contraction include AGT, ACTA2, ACTG2, CALD1 and CACNA1S.

\subsection{PRM analysis for protein quantification}


To validate the results of the proteomic analysis, 18 up-regulated DEPs related to liver diseases and gastrointestinal system were chosen for further study, their expression in gastric mucosa was measured by PRM and 17 of them were successfully quantified. The protein quantification results are shown in Table 2. The heatmap and boxplot are shown in Fig. 8. In accordance with LFQ, these proteins were significantly up-regulated in Ph group and Inter group compared with Nor group, the same trend was also observed in Inter group compared with Ph group.

Table 2

17 differentially expressed proteins validated by parallel reaction monitoring quantification (PRM).

\begin{tabular}{|c|c|c|c|c|c|c|c|c|c|}
\hline $\begin{array}{l}\text { Protein } \\
\text { Accession }\end{array}$ & $\begin{array}{l}\text { Protein } \\
\text { Gene }\end{array}$ & $\begin{array}{l}\text { Inter/Nor } \\
\text { Ratio }\end{array}$ & $\begin{array}{l}\text { Inter/Nor } \\
\text { p-value }\end{array}$ & $\begin{array}{l}\mathrm{PH} / \mathrm{Nor} \\
\text { Ratio }\end{array}$ & $\begin{array}{l}\mathrm{PH} / \text { Nor } \\
\text { p-value }\end{array}$ & $\begin{array}{l}\text { PH/Nor } \\
\text { Ratio(TMT) }\end{array}$ & $\begin{array}{l}\text { Inter/PH } \\
\text { Ratio }\end{array}$ & $\begin{array}{l}\text { Inter/PH } \\
\text { p-value }\end{array}$ & $\begin{array}{l}\text { Inter/PH } \\
\text { Ratio(TMT) }\end{array}$ \\
\hline Q16527 & CSRP2 & 3.38 & 4.54E-03 & 2.42 & $\begin{array}{l}1.54 \mathrm{E}- \\
04\end{array}$ & 1.99 & 1.40 & $\begin{array}{l}1.71 \mathrm{E}- \\
01\end{array}$ & 1.16 \\
\hline P24821 & TNC & 14.75 & 8.51E-03 & 3.66 & $\begin{array}{l}1.34 \mathrm{E}- \\
02\end{array}$ & 2.58 & 4.03 & $\begin{array}{l}1.67 \mathrm{E}- \\
02\end{array}$ & 1.30 \\
\hline Q15746 & MYLK & 2.67 & 5.15E-03 & 1.45 & $\begin{array}{l}1.53 \mathrm{E}- \\
02\end{array}$ & 1.16 & 1.84 & $\begin{array}{l}2.09 \mathrm{E}- \\
02\end{array}$ & 1.07 \\
\hline P21333 & FLNA & 2.64 & 8.52E-03 & 1.41 & $\begin{array}{l}5.06 \mathrm{E}- \\
02\end{array}$ & 1.11 & 1.87 & $\begin{array}{l}2.93 \mathrm{E}- \\
02\end{array}$ & 1.03 \\
\hline P50416 & CPT1A & 1.76 & 3.79E-02 & 1.53 & $\begin{array}{l}2.39 \mathrm{E}- \\
02\end{array}$ & 1.31 & 1.15 & $\begin{array}{l}4.30 \mathrm{E}- \\
01\end{array}$ & 1.11 \\
\hline P08572 & COL4A2 & 2.63 & 3.29E-03 & 2.02 & $\begin{array}{l}2.46 \mathrm{E}- \\
03\end{array}$ & 1.60 & 1.31 & $\begin{array}{l}2.05 \mathrm{E}- \\
01\end{array}$ & 1.09 \\
\hline P56199 & ITGA1 & 3.04 & 2.00E-02 & 2.19 & $\begin{array}{l}4.24 \mathrm{E}- \\
02\end{array}$ & 1.46 & 1.39 & $\begin{array}{l}3.01 \mathrm{E}- \\
01\end{array}$ & 1.00 \\
\hline P12110 & COL6A2 & 3.24 & 4.41E-03 & 1.64 & $\begin{array}{l}2.65 \mathrm{E}- \\
02\end{array}$ & 1.24 & 1.97 & $\begin{array}{l}1.93 \mathrm{E}- \\
02\end{array}$ & 1.03 \\
\hline P12109 & COL6A1 & 2.62 & 4.82E-03 & 1.56 & $\begin{array}{l}3.78 \mathrm{E}- \\
02\end{array}$ & 1.23 & 1.69 & $\begin{array}{l}3.42 \mathrm{E}- \\
02\end{array}$ & 0.88 \\
\hline Q9BX66 & SORBS1 & 2.10 & $1.52 \mathrm{E}-03$ & 1.42 & $\begin{array}{l}2.74 \mathrm{E}- \\
02\end{array}$ & 1.43 & 1.48 & $\begin{array}{l}1.69 \mathrm{E}- \\
02\end{array}$ & 1.21 \\
\hline 095573 & ACSL3 & 1.76 & 2.33E-02 & 1.51 & $\begin{array}{l}2.09 \mathrm{E}- \\
02\end{array}$ & 1.55 & 1.16 & $\begin{array}{l}3.70 \mathrm{E}- \\
01\end{array}$ & 0.78 \\
\hline 043294 & TGFB1I1 & 3.21 & 3.93E-03 & 1.78 & $\begin{array}{l}3.61 \mathrm{E}- \\
03\end{array}$ & 1.72 & 1.80 & $\begin{array}{l}3.24 \mathrm{E}- \\
02\end{array}$ & 1.02 \\
\hline P43121 & MCAM & 1.94 & 9.74E-03 & 1.34 & $\begin{array}{l}1.26 \mathrm{E}- \\
01\end{array}$ & 1.01 & 1.45 & $\begin{array}{l}6.57 \mathrm{E}- \\
02\end{array}$ & 1.26 \\
\hline Q9NR12 & PDLIM7 & 3.26 & 3.36E-03 & 1.54 & $\begin{array}{l}1.10 \mathrm{E}- \\
02\end{array}$ & 1.23 & 2.11 & $\begin{array}{l}1.14 \mathrm{E}- \\
02\end{array}$ & 1.24 \\
\hline Q9HBL0 & TNS1 & 2.80 & 3.51E-03 & 1.39 & $\begin{array}{l}1.12 \mathrm{E}- \\
01\end{array}$ & 1.30 & 2.02 & $\begin{array}{l}1.05 \mathrm{E}- \\
02\end{array}$ & 1.20 \\
\hline Q12805 & EFEMP1 & 3.23 & $9.02 \mathrm{E}-04$ & 2.90 & $\begin{array}{l}3.70 \mathrm{E}- \\
04\end{array}$ & 2.09 & 1.11 & $\begin{array}{l}5.64 \mathrm{E}- \\
01\end{array}$ & 1.43 \\
\hline Q9UBX5 & FBLN5 & 4.56 & 5.40E-04 & 4.72 & $\begin{array}{l}1.03 \mathrm{E}- \\
03\end{array}$ & 2.74 & 0.97 & $\begin{array}{l}8.78 \mathrm{E}- \\
01\end{array}$ & 1.53 \\
\hline
\end{tabular}

\section{Discussion}


Currently, the severity of GOV caused by PH is critical for the prognosis of patients with decompensated liver cirrhosis. Most of the need lies in the detection of liver cirrhosis patients at risk of occurrence and the progression of $\mathrm{PH}$, and early diagnosis and treatment may greatly contribute to enhancing the survival of such patients. Decompensated liver cirrhosis presents not only as GOV but also PHG. The severity of swelling and reddening of gastric mucosa(8), interstitial vascular ectasia, spindle cell proliferation and fibrohyalinosis(9) reflect the degree of PHG and are associated with severity of liver disease. Monitoring changes in the gastric mucosa proteome may have an advantage in the diagnosis of decompensated liver cirrhosis. However, targeted proteomics, which identifies promising biomarkers of disease activity and organ involvement, is rarely involved in non-invasive method for detection and diagnosis of liver cirrhosis induced $\mathrm{PH}$. Our group devoted to the research of proteomics in liver disease $(10,11)$. To the best of our knowledge, no proteomic analysis of gastric mucosa has been reported for the discovery of biomarkers and to describe the involvement of related biological pathways in liver cirrhosis induced $\mathrm{PH}$. In this study, we performed a comparative analysis of the gastric mucosa proteome to obtain insights into the quantitative assessment and prognosis in liver cirrhosis patients via LC-MS/MS and PRM. As a result, we found that 423 proteins were differentially expressed in gastric from PHG patients before and after endoscopic cyanoacrylate injection compared to that from normal controls. Due to the importance of pathogenesis and early diagnosis of PHG, we studied the characterization and function of some differentially expressed proteins in depth.

According to KEGG function classification analysis, focal adhesion and vascular smooth muscle contraction pathway are enriched in PHG. In the process of liver fibrogenesis, focal adhesion connects hepatic stellate cells (HSCs) and ECM, and provides a direct sensor to the integrity of interaction with the extracellular environment, causing cell adhesion and migration $(12,13)$. The patients with liver cirrhosis exhibit a progression of vascular smooth muscle contraction dysfunction, which presents as an increased intrahepatic vasoconstriction and reduced systemic vascular resistance(14). The progress of PHG is related to hemodynamic alterations in the gastric mucosa, presenting as hemangiectasis(15), abnormal formation of arteriovenous shunts and blood flow augmentation(16).

Among these DEPs, PDLIM4 is the only protein which alters among the three groups, indicating cytoskeleton organization and stress fiber formation(17) may relate to development of PHG. Moreover, 17 DEPs about liver diseases and gastrointestinal system were further chosen and validated by PRM. There DEPs are up-regulated in PHG patients and even more after endoscopic cyanoacrylate injection, indicating their expression level is consistent with severity of PHG. Among these DEPs, MYLK, TNC, ITGA1, FLNA, COL6A1, COL6A2 and COL6A3 are enriched in focal adhesion pathway. MYLK participate in smooth muscle contraction pathway at the same time. Activation of MYLK triggers gastrointestinal smooth muscle contraction with an increase of intracellular $\mathrm{Ca}^{2+}\left[\mathrm{Ca}^{2+}\right]_{\mid}$. Compared with antrum muscles, fundus muscles have a higher level of MYLK expression(18), which may contribute to the mechanism of gastric motility. In addition, MYLK also mediates cell-cell and cellmatric adhesion(19). TNC can promote arterial smooth muscle cells proliferation and ECM elements deposition after stimulation of inflammatory cytokines and growth factors in cerebral arteries(20) and pulmonary arteries(21) by enhancing focal adhesion kinase phosphorylation(22). These mechanisms may contribute to TNC mediated vascular remodeling $(23,24)$ and participate in the pathogenesis of subarachnoid hemorrhage and pulmonary arterial hypertension. FLNA couples cell cytoskeleton to ECM and regulates integrin alpha-1 (ITGA1), thus affects the function of collagen and ECM remodeling(2528). With the development of liver fibrosis, FLNA can be activated in HSCs and may serve as a biomarker(29). Integrin modulates angiogenesis, regulates inflammation, and translates biliary injury into stimulation of matrix-producing mesenchymal cells in the process of fibrosis development(30). Thereinto, ITGA1 is a receptor for laminin and collagen, it is involved in cell adhesion and correlates with inflammatory activity and fibrosis(31). Collagen IV contributes to ECM structure and expresses extracellularly. It is structured by a heterotrimer of the alpha1(VI), alpha2(VI), and alpha3(VI) chains which are encoded by COL6A1, COL6A2, COL6A3, respectively(32).

Other validated proteins, though not enriched in the two pathways mentioned above, also play a role in the process of liver and gastrointestinal diseases. CPT1A and ACSL3, which are responsible for fatty acid oxidation, have been proved to stimulate gastric cancer and hepatocellular carcinoma cell growth and migration(33-35). MCAM (CD146) involves in actin cytoskeleton rearrangement, blood vessel endothelial cells remodeling and intercellular junction(36). CSRP2 expresses specifically in HSCs in liver and mediates the transdifferentiation of HSCs into myofibroblasts with the activation of TGF- $\beta(37)$. Focal adhesion 
protein TGFB1I1 (also known as Hic5) is induced by TGF-ßand regulates myofibroblast differentiation in liver(38). TNS1 is also localized to focal adhesions and acts as a bridge linking ECM and the actin cytoskeleton(39). EFEMP1 and FBLN5 are ECM proteins and highly express in portal fibroblasts, they have been proved to play a role in progressive liver fibrosis $(40,41)$. SORBS1 involves in cytoskeleton organization and insulin signaling pathway in human hepatoma cell line(42). PDLIM7 is composed of PDZ and LIM7 domain, the LIM7 domain is associated with progression of liver fibrosis in hepatitis C virus infected patients(43). Although the association with PHG is not quite clear, this study identified these DEPs as potential biomarkers on gastric mucosa for liver cirrhosis induced $\mathrm{PH}$. However, more studies are required to make sure their availability as predictive biomarkers and diagnostic targets.

\section{Conclusion}

In this study, we identified quantitative differences in expression of several proteins on gastric mucosa for PHG patients. This proteomic study demonstrates that a LFQ analysis can be useful in detection of novel predictive biomarkers, and 17 promising proteins are further validated by PRM analysis. Our findings will provide a prospect for non-invasive early diagnosis and prediction of severity of liver cirrhosis induced portal hypertension, but more mechanisms of the interaction of these DEPs and their effect on the progression of PHG require further research.

\section{Methods}

\subsection{Clinical Samples}

From March 2020 to June 2020, decompensated liver cirrhosis patients meeting the criteria below were admitted to the Department of Digestive Medicine, Shenzhen Hospital of Southern Medical University. Inclusion criteria included: 1) an age range of 15-85 years, 2) computed tomography (CT), laboratory examination and endoscopy confirmed the diagnosis of PHG according to Portal Hypertensive Bleeding in Cirrhosis: Risk Stratification, Diagnosis, and Management: 2016 Practice Guidance by the American Association for the Study of Liver Diseases, 3) Moderate to severe esophageal varices have no bleeding, but there is an obvious risk of bleeding, endoscopic primary prevention treatment is needed, and 4) Cases with a history of esophageal varices rupture and bleeding and secondary endoscopic prophylaxis. Exclusion criteria included acute EGVB, presinus and retrosinus portal hypertension portal hypertension, esophageal or gastric submucosal tumor, hypertrophic gastritis, and patients who have endoscopic examination contraindications. All individuals were excluded helicobacter pylori infection by Carbon-13 urea breath test or histologic examination of gastric mucosa. 5 healthy individuals who underwent physical examinations with no history of alcoholic or viral hepatitis and helicobacter pylori infection were assigned to the normal control group (Nor group), 5 liver cirrhosis patients with gastroscopy confirmed PHG were assigned to PHG group (Ph group). Ph group patients underwent gastroscopy 1 week after endoscopic cyanoacrylate injection (Inter group). Gastric mucosa samples were collected during gastroscopy by a biopsy forceps from the middle part of greater curvature by gastroscopic biopsy in Department of Endoscopy, Shenzhen Hospital of Southern Medical University. All samples were assigned to LFQ analysis, 2 individuals of each group were randomly selected to participate in PRM verification. Besides, 4 healthy individuals and 5 liver cirrhosis patients meeting the criteria above were assigned to PRM analysis. The study design was approved by the Shenzhen Hospital of Southern Medical University Ethic Committee complying with Declaration of Helsinki, Operational Guideline for the Ethic Review of Biomedical Research involving Human Subject [(2016) No.11] and International Ethical Guidelines for Biomedical Research Involving Human Subjects, CIOMS. All participants have signed the written informed consent.

\subsection{Protein Extraction and LS-MS/MS Analysis}

Proteins extraction and LS-MS/MS analysis were performed according to the method of Zheng X et al (44). Gastric mucosa samples were grinded by liquid nitrogen into cell powder and then transferred to a 5-mL centrifuge tube. After that, four volumes of lysis buffer (8 M urea, 1\% Protease Inhibitor Cocktail) were added to the cell powder, followed by sonication three times on ice using a high intensity ultrasonic processor (Scientz). (Note: For PTM experiments, inhibitors were also added to the lysis buffer, e.g. $3 \mu \mathrm{M}$ TSA and $50 \mathrm{mM}$ NAM for acetylation.) The remaining debris was removed by centrifugation at 
$12,000 \mathrm{~g}$ at $4^{\circ} \mathrm{C}$ for $10 \mathrm{~min}$. Finally, the supernatant was collected and the protein concentration was determined with BCA kit according to the manufacturer's instructions.

For digestion, the protein solution was reduced with $5 \mathrm{mM}$ dithiothreitol for $30 \mathrm{~min}$ at $56^{\circ} \mathrm{C}$ and alkylated with $11 \mathrm{mM}$ iodoacetamide for $15 \mathrm{~min}$ at room temperature in darkness. The protein sample was then diluted by adding $100 \mathrm{mM}$ TEAB to urea concentration less than 2M. Finally, trypsin was added at 1:50 trypsin-to-protein mass ratio for the first digestion overnight and 1:100 trypsin-to-protein mass ratio for a second 4 h-digestion.

The peptides after trypsin digestion were dissolved in $0.1 \%$ formic acid (solvent $A$ ), directly loaded onto a home-made reversedphase analytical column (15-cm length, $75 \mu \mathrm{m}$ i.d.). The gradient was comprised of an increase from $6-23 \%$ solvent $B(0.1 \%$ formic acid in $98 \%$ acetonitrile) over $26 \mathrm{~min}, 23-35 \%$ in $8 \mathrm{~min}$ and climbing to $80 \%$ in $3 \mathrm{~min}$ then holding at $80 \%$ for the last 3 min, all at a constant flow rate of $400 \mathrm{~nL} / \mathrm{min}$ on an EASY-nLC 1000 UPLC system.

The peptides were subjected to NSI source followed by tandem mass spectrometry (MS/MS) in Q ExactiveTM Plus (Thermo) coupled online to the UPLC. The electrospray voltage applied was $2.0 \mathrm{kV}$. The $\mathrm{m} / \mathrm{z}$ scan range was 350 to 1800 for full scan, and intact peptides were detected in the Orbitrap at a resolution of 70,000. Peptides were then selected for MS/MS using NCE setting as 28 and the fragments were detected in the Orbitrap at a resolution of 17,500. A data-dependent procedure that alternated between one MS scan followed by $20 \mathrm{MS} / \mathrm{MS}$ scans with 15.0s dynamic exclusion. Automatic gain control (AGC) was set at 5E4. Fixed first mass was set as $100 \mathrm{~m} / \mathrm{z}$.

\subsection{Database Search}

The resulting MS/MS data were processed using Maxquant search engine (v1.6.6.0). Tandem mass spectra were searched against human uniprot database [Homo_sapiens_9606_SP_20200509 (20366 entries)] concatenated with reverse decoy database. Trypsin/P was specified as cleavage enzyme allowing up to 4 missing cleavages. The mass tolerance for precursor ions was set as 20 ppm in First search and 5 ppm in Main search, and the mass tolerance for fragment ions was set as 0.02 Da. Carbamidomethyl on Cys was specified as fixed modification. Acetylation on protein N-terminal, oxidation on Met and deamidation (NQ) were specified as variable modifications. FDR was adjusted to $<1 \%$ and minimum score for modified peptides was set $>40$.

\subsection{Bioinformatics analyses}

The proteins were defined as differentially expressed if the fold-change of pairwise comparison was $\geq 1.5$ or $\leq 1 / 1.5$ and the $P$ value $<0.05$. Next, the DEPs were subjected to gene ontology (GO) analysis by UniProt-GOA database (www. http://www.ebi.ac.uk/GOA/) and matched against the Kyoto Encyclopedia of Genes and Genomes (KEGG) database by the KEGG Automatic Annotation Server (KAAS). P $<0.05$ in Fisher's exact test was considered significant. Protein-protein interaction (PPI) networks were created for these proteins using the STRING database (v. 11). Differential expressed proteins interaction was extracted according to confidence score >0.7. R Package "networkD3" tool was used to visualize the differential protein interaction network. (45)

\subsection{Parallel Reaction Monitoring (PRM)}

We use PRM analysis to verify protein expression levels according to the method of Zhang P et al (46). The resulting MS data were processed using Skyline (v.3.6). Peptide settings: enzyme was set as Trypsin [KR/P], Max missed cleavage set as 2 . The peptide length was set as 8-25, Variable modification was set as Carbamidomethyl on Cys and oxidation on Met, and max variable modifications was set as 3 . Transition settings: precursor charges were set as 2,3 , ion charges were set as 1 , 2, ion types were set as b, y, p. The product ions were set as from ion 3 to last ion, the ion match tolerance was set as $0.02 \mathrm{Da}$.

\subsection{Statistics}

All data were processed using Microsoft Excel 2019 (Microsoft Corporation, Redmond, WA, USA). Data were expressed as the mean \pm SEM, and comparisons of differences between two groups were analyzed using a one-way analysis of variance (ANOVA). Count data are expressed as a ratio, and the $\chi^{2}$ test was used for comparisons of differences between groups. $p<$ 
0.05 was designated to be of statistical significance. Statistical tests were conducted using SPSS v26.0 (SPSS, Chicago, IL, USA).

\section{Abbreviations}

BP: biological processes; CC: cellular components; CT: computed tomography; DEPs: differentially expressed proteins; EGVB: esophagogastric variceal bleeding; ECM: extracellular matrix; GO: Gene Ontology; GOV: gastroesophageal varices; HSCs: hepatic stellate cells; KEGG: Kyoto Encyclopedia of Genes and Genomes; LFQ: label-free quantitative; MF: molecular functions; MRI: magnetic resonance imaging; PH: portal hypertension; PHG: portal hypertensive gastropathy; PPI: protein-protein interaction; PRM: parallel reaction monitoring; TE: transient elastography.

\section{Declarations}

\section{Ethics approval and consent to participate:}

Ethical approval for this study was obtained from the Shenzhen Hospital of Southern Medical University Ethic Committee (NYSZYYEC20200005) and clinical study registration was completed (ChiCTR2000029840). All subjects gave informed consent, and all treatment and management measures were monitored by the attending physicians.

\section{Availability of data and materials:}

The datasets used and/or analyzed during the current study are available from the corresponding author on reasonable request.

\section{Competing interests:}

The authors declare that they have no competing interests.

\section{Funding:}

This work was supported by research grants provided by National Natural Science Foundation of China (No. 81800503 and No. 81974070), the Basic Research Subject of Science and Technology plan in Bao' an District (No. 2019JD444).

\section{Authors contributions:}

YZ designed the project and collected the samples and prepared figure 2. WX drafted the work and prepared figure 1 and 3-8. WH collected the data and prepared table 1. FW and YZ performed the analyses, evaluated the results and prepared table 2. JGX and WG made substantial contributions to the conception. All authors read and approved the final manuscript.

\section{Acknowledgement:}

We thank PTM Biolabs (Hangzhou, China) for proteomic quantification.

\section{References}

1. Fukui H, Saito H, Ueno Y, Uto H, Obara K, Sakaida I, et al. Evidence-based clinical practice guidelines for liver cirrhosis 2015. J. Gastroenterol. 2016;51(7):629-50; http.//dx.doi.org/10.1007/s00535-016-1216-y 
2. Garcia-Tsao G, Abraldes J, Berzigotti A, Bosch J. Portal hypertensive bleeding in cirrhosis: Risk stratification, diagnosis, and management: 2016 practice guidance by the American Association for the study of liver diseases. Hepatology. 2017;65(1):310-35; http.//dx.doi.org/10.1002/hep.28906

3. de Franchis R. Revising consensus in portal hypertension: report of the Baveno V consensus workshop on methodology of diagnosis and therapy in portal hypertension. J. Hepatol. 2010;53(4):762-8; http.//dx.doi.org/10.1016/j.jhep.2010.06.004

4. Tanoue K, Hashizume M, Wada H, Ohta M, Kitano S, Sugimachi K. Effects of endoscopic injection sclerotherapy on portal hypertensive gastropathy: a prospective study. Gastrointest. Endosc. 1992;38(5):582-5; http.//dx.doi.org/10.1016/s00165107(92)70522-7

5. Zhu Y, Wang F, Zhou Y, Xia G, Dong L, He W, et al. Blue laser magnifying endoscopy in the diagnosis of chronic gastritis. Exp. Ther. Med. 2019;18(3):1993-2000; http.//dx.doi.org/10.3892/etm.2019.7811

6. Bella M, Casas M, Vergara M, Brullet E, Junquera F, Martínez-Bauer E, et al. Utility of histology for the diagnosis of portal hypertensive gastroenteropathy. Concordance between the endoscopic image and gastrointestinal biopsies. Role of the CD34 marker. Gastroenterol. Hepatol. 2019;42(3):150-6; http.//dx.doi.org/10.1016/j.gastrohep.2018.09.008

7. Westerhoff M, Tretiakova M, Hovan L, Miller J, Noffsinger A, Hart J. CD61, CD31, and CD34 improve diagnostic accuracy in gastric antral vascular ectasia and portal hypertensive gastropathy: An immunohistochemical and digital morphometric study. Am. J. Surg. Pathol. 2010;34(4):494-501; http.//dx.doi.org/10.1097/PAS.0b013e3181d38f0a

8. Fontana R, Sanyal A, Mehta S, Doherty M, Neuschwander-Tetri B, Everson G, et al. Portal hypertensive gastropathy in chronic hepatitis $\mathrm{C}$ patients with bridging fibrosis and compensated cirrhosis: results from the HALT-C trial. Am. J. Gastroenterol. 2006;101(5):983-92; http.//dx.doi.org/10.1111/j.1572-0241.2006.00461.x

9. Payen J, Calès P, Voigt J, Barbe S, Pilette C, Dubuisson L, et al. Severe portal hypertensive gastropathy and antral vascular ectasia are distinct entities in patients with cirrhosis. Gastroenterology. 1995;108(1):138-44;

http.//dx.doi.org/10.1016/0016-5085(95)90018-7

10. Xu J, Zhu Y, Wang F, Zhou Y, Xia G, Xu W. ICMT contributes to hepatocellular carcinoma growth, survival, migration and chemoresistance via multiple oncogenic pathways. Biochem Biophys Res Commun. 2019;518(3):584-9; http.//dx.doi.org/10.1016/j.bbrc.2019.08.094

11. Zhu Y, Xu J, Hu W, Wang F, Zhou Y, Xu W, et al. TFAM depletion overcomes hepatocellular carcinoma resistance to doxorubicin and sorafenib through AMPK activation and mitochondrial dysfunction. Gene. 2020;753:144807; http.//dx.doi.org/10.1016/j.gene.2020.144807

12. Carloni V, Romanelli R, Pinzani M, Laffi G, Gentilini P. Focal adhesion kinase and phospholipase C gamma involvement in adhesion and migration of human hepatic stellate cells. Gastroenterology. 1997;112(2):522-31; http.//dx.doi.org/10.1053/gast.1997.v112.pm9024306

13. Parsons C, Takashima M, Rippe R. Molecular mechanisms of hepatic fibrogenesis. J. Gastroenterol. Hepatol. 2007:S7984; http.//dx.doi.org/10.1111/j.1440-1746.2006.04659.x

14. Kajita M, Murata T, Horiguchi K, lizuka M, Hori M, Ozaki H. iNOS expression in vascular resident macrophages contributes to circulatory dysfunction of splanchnic vascular smooth muscle contractions in portal hypertensive rats. Am J Physiol Heart Circ Physiol. 2011;300(3):H1021-31; http.//dx.doi.org/10.1152/ajpheart.00563.2009

15. Iwao T, Toyonaga A, Sumino M, Takagi K, Oho K, Nishizono M, et al. Portal hypertensive gastropathy in patients with cirrhosis. Gastroenterology. 1992;102(6):2060-5; http.//dx.doi.org/10.1016/0016-5085(92)90332-s

16. Albillos A, Colombato L, Enriquez R, Ng O, Sikuler E, Groszmann R. Sequence of morphological and hemodynamic changes of gastric microvessels in portal hypertension. Gastroenterology. 1992;102(6):2066-70; http.//dx.doi.org/10.1016/0016-5085(92)90333-t

17. Vallenius T, Scharm B, Vesikansa A, Luukko K, Schäfer R, Mäkelä T. The PDZ-LIM protein RIL modulates actin stress fiber turnover and enhances the association of alpha-actinin with F-actin. Exp. Cell Res. 2004;293(1):117-28;

http.//dx.doi.org/10.1016/j.yexcr.2003.09.004

Page 10/18 
18. Li W, Sasse K, Bayguinov Y, Ward S, Perrino BJJodr. Contractile Protein Expression and Phosphorylation and Contractility of Gastric Smooth Muscles from Obese Patients and Patients with Obesity and Diabetes. J Diabetes Res.

2018;2018:8743874; http.//dx.doi.org/10.1155/2018/8743874

19. Lin J, He Y, Chen L, Chen X, Zang S, Lin W. MYLK promotes hepatocellular carcinoma progression through regulating cytoskeleton to enhance epithelial-mesenchymal transition. Clin Exp Med. 2018;18(4):523-33;

http.//dx.doi.org/10.1007/s10238-018-0509-2

20. Borel C, McKee A, Parra A, Haglund M, Solan A, Prabhakar V, et al. Possible role for vascular cell proliferation in cerebral vasospasm after subarachnoid hemorrhage. Stroke. 2003;34(2):427-33;

http.//dx.doi.org/10.1161/01.str.0000053848.06436.ab

21. Morrell N, Adnot S, Archer S, Dupuis J, Jones P, MacLean M, et al. Cellular and molecular basis of pulmonary arterial hypertension. J. Am. Coll. Cardiol. 2009;54:S20-31; http.//dx.doi.org/10.1016/j.jacc.2009.04.018

22. Zagzag D, Shiff B, Jallo G, Greco M, Blanco C, Cohen H, et al. Tenascin-C promotes microvascular cell migration and phosphorylation of focal adhesion kinase. Cancer Res. 2002;62(9):2660-8;

23. Suzuki H, Kanamaru K, Suzuki Y, Aimi Y, Matsubara N, Araki T, et al. Tenascin-C is induced in cerebral vasospasm after subarachnoid hemorrhage in rats and humans: a pilot study. Neurol. Res. 2010;32(2):179-84;

http.//dx.doi.org/10.1179/174313208x355495

24. Wallner K, Sharifi B, Shah P, Noguchi S, DeLeon H, Wilcox J. Adventitial remodeling after angioplasty is associated with expression of tenascin mRNA by adventitial myofibroblasts. J. Am. Coll. Cardiol. 2001;37(2):655-61; http.//dx.doi.org/10.1016/s0735-1097(00)01117-7

25. Xu Y, Bismar T, Su J, Xu B, Kristiansen G, Varga Z, et al. Filamin A regulates focal adhesion disassembly and suppresses breast cancer cell migration and invasion. J Exp Med. 2010;207(11):2421-37; http.//dx.doi.org/10.1084/jem.20100433

26. Krebs K, Ruusmann A, Simonlatser G, Velling TJEjocb. Expression of FLNa in human melanoma cells regulates the function of integrin a1 $\beta 1$ and phosphorylation and localisation of PKB/AKT/ERK1/2 kinases. Eur. J. Cell Biol.

2015;94(12):564-75; http.//dx.doi.org/10.1016/j.ejcb.2015.10.006

27. Karimi A, Milewicz D. Structure of the Elastin-Contractile Units in the Thoracic Aorta and How Genes That Cause Thoracic Aortic Aneurysms and Dissections Disrupt This Structure. Can J Cardiol. 2016;32(1):26-34;

http.//dx.doi.org/10.1016/j.cjca.2015.11.004

28. Mohammadi H, Pinto V, Wang Y, Hinz B, Janmey P, McCulloch C. Filamin A Mediates Wound Closure by Promoting Elastic Deformation and Maintenance of Tension in the Collagen Matrix. J Invest Dermatol. 2015;135(11):2852-61; http.//dx.doi.org/10.1038/jid.2015.251

29. Zhang H, Chen F, Fan X, Lin C, Hao Y, Wei H, et al. Quantitative Proteomic analysis on Activated Hepatic Stellate Cells reversion Reveal STAT1 as a key regulator between Liver Fibrosis and recovery. Sci. Rep. 2017;7:44910; http.//dx.doi.org/10.1038/srep44910

30. Patsenker E, Stickel F. Role of integrins in fibrosing liver diseases. American journal of physiology. Gastrointestinal liver physiology. 2011;301(3):G425-34; http.//dx.doi.org/10.1152/ajpgi.00050.2011

31. Patsenker E, Popov Y, Stickel F, Schneider V, Ledermann M, Sägesser H, et al. Pharmacological inhibition of integrin alphavbeta3 aggravates experimental liver fibrosis and suppresses hepatic angiogenesis. Hepatology. 2009;50(5):150111; http.//dx.doi.org/10.1002/hep.23144

32. Cescon M, Gattazzo F, Chen P, Bonaldo PJJocs. Collagen VI at a glance. J. Cell Sci. 2015;128(19):3525-31; http.//dx.doi.org/10.1242/jcs.169748

33. Wang L, Li C, Song Y, Yan Z. Inhibition of carnitine palmitoyl transferase 1A-induced fatty acid oxidation suppresses cell progression in gastric cancer. Archives of biochemistry biophysics. 2020;696:108664;

http.//dx.doi.org/10.1016/j.abb.2020.108664

34. Xu A, Wang B, Fu J, Qin W, Yu T, Yang Z, et al. Diet-induced hepatic steatosis activates Ras to promote hepatocarcinogenesis via CPT1a. Cancer Lett. 2019;442:40-52; http.//dx.doi.org/10.1016/j.canlet.2018.10.024

Page $11 / 18$ 
35. Ndiaye H, Liu J, Hall A, Minogue S, Morgan M, Waugh M. Immunohistochemical staining reveals differential expression of ACSL3 and ACSL4 in hepatocellular carcinoma and hepatic gastrointestinal metastases. Biosci. Rep. 2020;40(4); http.//dx.doi.org/10.1042/bsr20200219

36. Ouhtit A, Gaur R, Abd Elmageed Z, Fernando A, Thouta R, Trappey A, et al. Towards understanding the mode of action of the multifaceted cell adhesion receptor CD146. Biochim. Biophys. Acta. 2009;1795(2):130-6;

http.//dx.doi.org/10.1016/j.bbcan.2009.01.002

37. Herrmann J, Borkham-Kamphorst E, Haas U, Van de Leur E, Fraga M, Esteller M, et al. The expression of CSRP2 encoding the LIM domain protein CRP2 is mediated by TGF-beta in smooth muscle and hepatic stellate cells. Biochem Biophys Res Commun. 2006;345(4):1526-35; http.//dx.doi.org/10.1016/j.bbrc.2006.05.076

38. Varney S, Betts C, Zheng R, Wu L, Hinz B, Zhou J, et al. Hic-5 is required for myofibroblast differentiation by regulating mechanically dependent MRTF-A nuclear accumulation. J. Cell Sci. 2016;129(4):774-87;

http.//dx.doi.org/10.1242/jcs.170589

39. Chen H, Duncan I, Bozorgchami H, Lo S. Tensin1 and a previously undocumented family member, tensin2, positively regulate cell migration. Proc. Natl. Acad. Sci. U. S. A. 2002;99(2):733-8; http.//dx.doi.org/10.1073/pnas.022518699

40. Chen Y, Gilbert M, Grochowski C, McEldrew D, Llewellyn J, Waisbourd-Zinman O, et al. A genome-wide association study identifies a susceptibility locus for biliary atresia on 2p16.1 within the gene EFEMP1. PLoS Genet. 2018;14(8):e1007532; http.//dx.doi.org/10.1371/journal.pgen.1007532

41. Bracht T, Schweinsberg V, Trippler M, Kohl M, Ahrens M, Padden J, et al. Analysis of disease-associated protein expression using quantitative proteomics-fibulin-5 is expressed in association with hepatic fibrosis. J. Proteome Res.

2015;14(5):2278-86; http.//dx.doi.org/10.1021/acs.jproteome.5b00053

42. Lin W, Huang $\mathrm{C}$, Liu M, Chang H, Chen $\mathrm{Y}$, Tai T, et al. Cloning, mapping, and characterization of the human sorbin and SH3 domain containing 1 (SORBS1) gene: a protein associated with c-Abl during insulin signaling in the hepatoma cell line Hep3B. Genomics. 2001;74(1):12-20; http.//dx.doi.org/10.1006/geno.2001.6541

43. Ibrahim M, Salama H, Abd El Rahman M, Dawood R, Bader El Din N, Salem H, et al. Three Gene Signature for Predicting the Development of Hepatocellular Carcinoma in Chronically Infected Hepatitis C Virus Patients. J Interferon Cytokine Res. 2016;36(12):698-705; http.//dx.doi.org/10.1089/jir.2016.0042

44. Zheng X, Yang Q, Zhao L, Apaliya M, Zhang X, Zhang H. Crosstalk between proteins expression and lysine acetylation in response to patulin stress in Rhodotorula mucilaginosa. Sci. Rep. 2017;7(1):13490; http.//dx.doi.org/10.1038/s41598017-14078-5

45. Wang Y, Hu B, Du S, Gao S, Chen X, Chen D. Proteomic Analyses Reveal the Mechanism of Dunaliella salina Ds-26-16 Gene Enhancing Salt Tolerance in Escherichia coli. PLoS One. 2016;11(5):e0153640;

http.//dx.doi.org/10.1371/journal.pone.0153640

46. Zhang P, Zhu Y, Luo X, Zhou S. Comparative proteomic analysis provides insights into the complex responses to Pseudoperonospora cubensis infection of cucumber (Cucumis sativus L.). Sci. Rep. 2019;9(1):9433;

http.//dx.doi.org/10.1038/s41598-019-45111-4

\section{Figures}




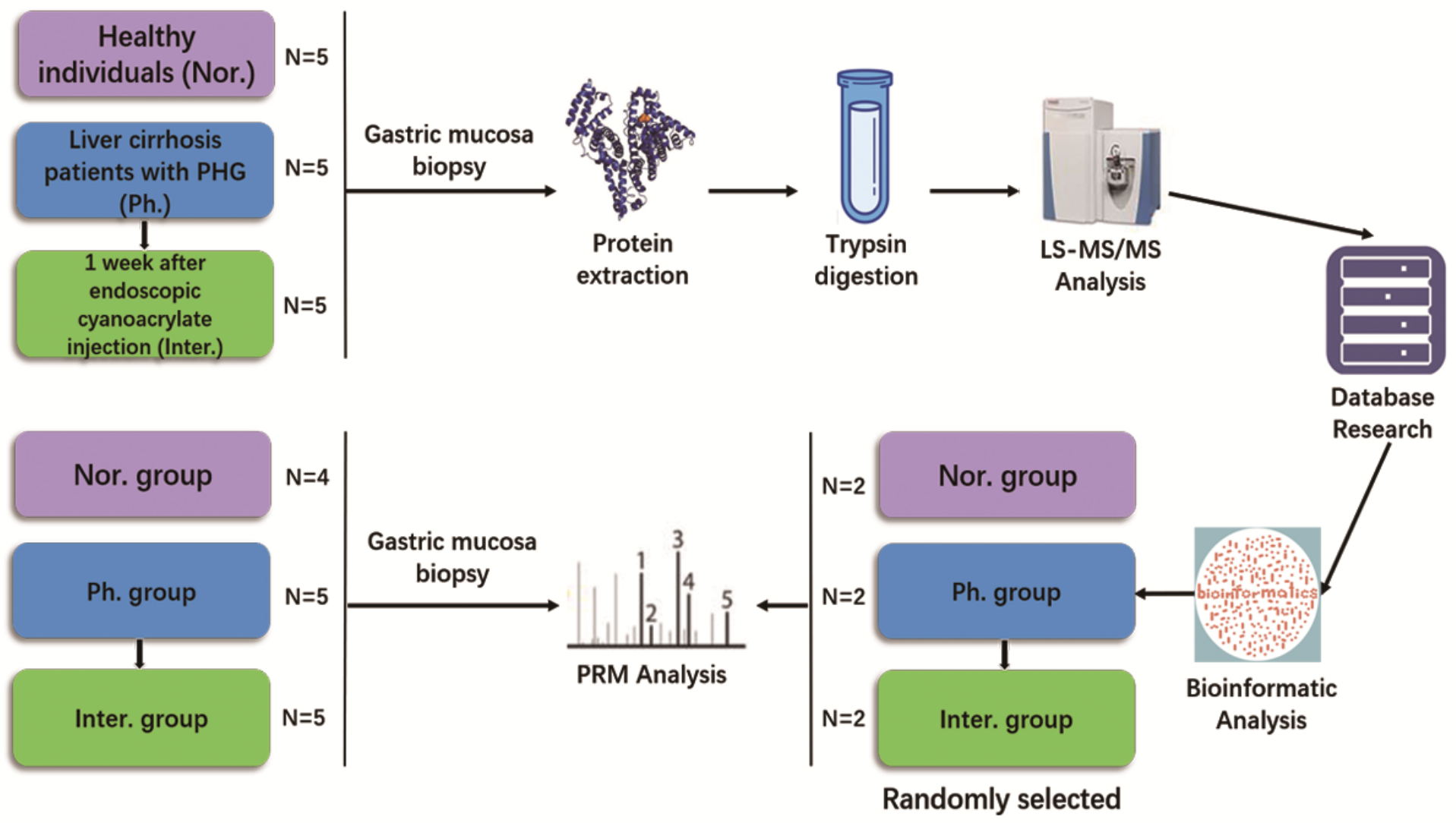

Figure 1

Workflow describing LFQ and PRM analysis. Proteins from samples were digested by trypsin and analyzed by LS-MS/MS. The differentially expressed proteins were analyzed by database researches and validated by PRM.
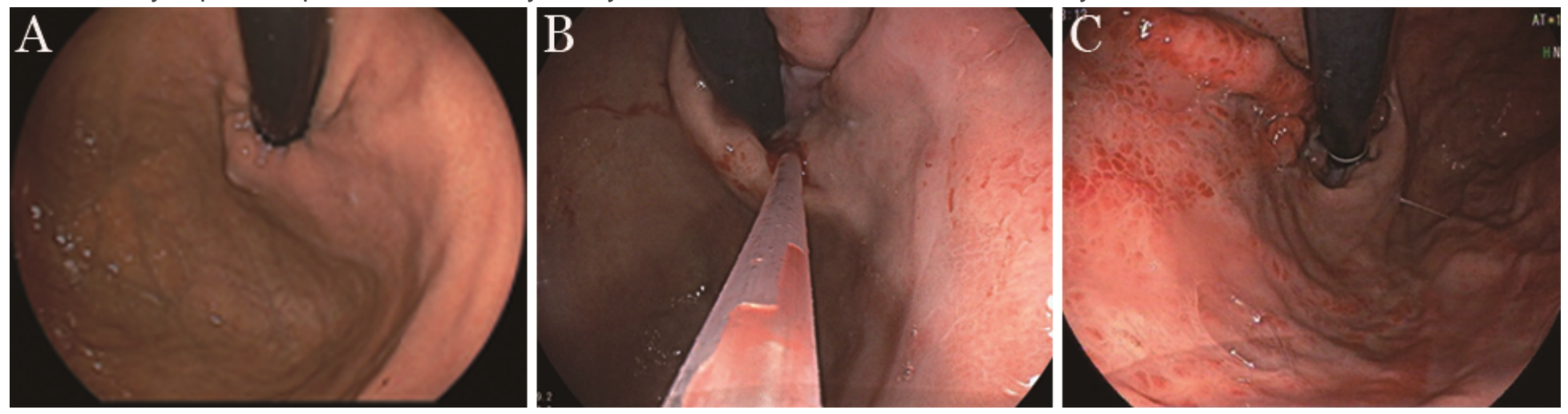

Figure 2

Gastroscopic appearance of healthy volunteers and decompensated liver cirrhosis patients. The gastroscopic photographs show (A) normal appearance of esophagus and fundus, (B) severe esophageal varices and mild PHG and (C) esophageal varices alleviation and $\mathrm{PHG}$ exacerbation after endoscopic cyanoacrylate injection. 


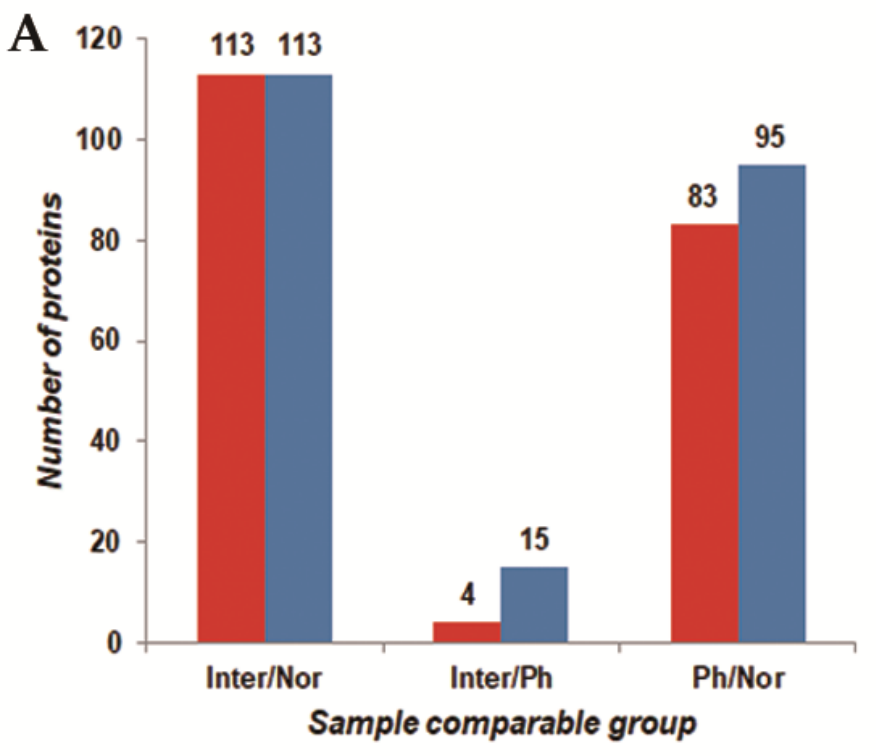

=Up-regulated $\quad$ Down-regulated
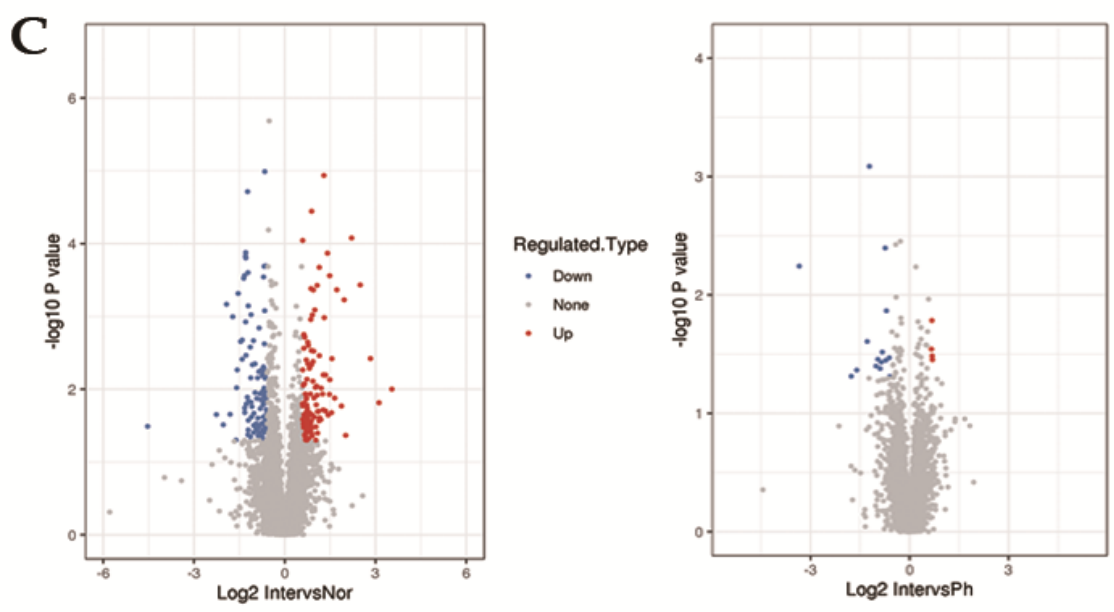

B

IntervsNor

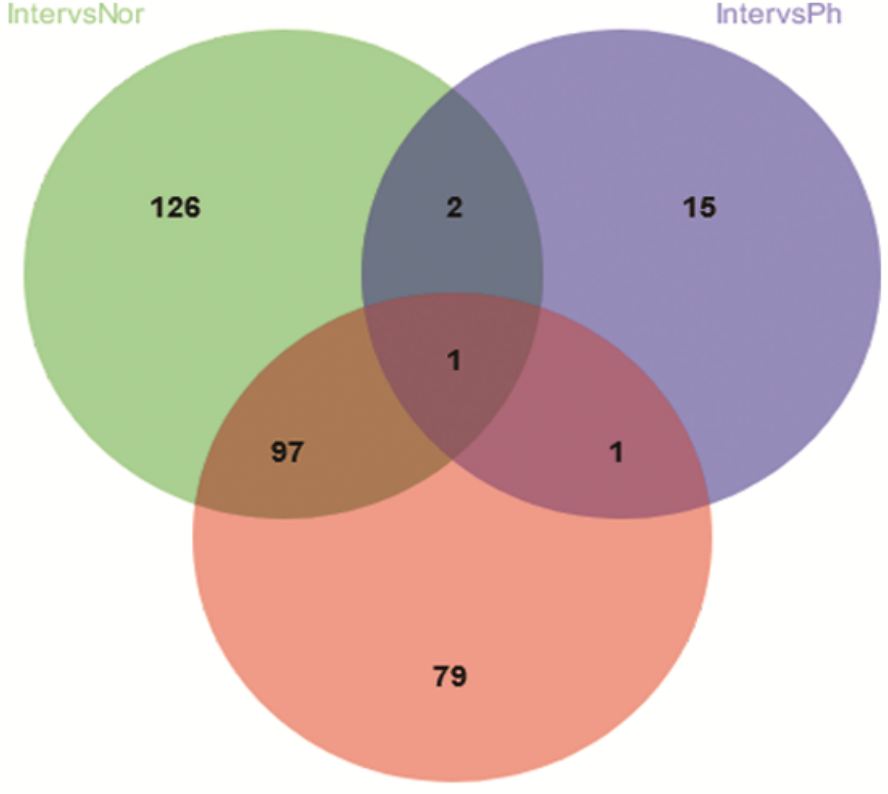

PhvsNor

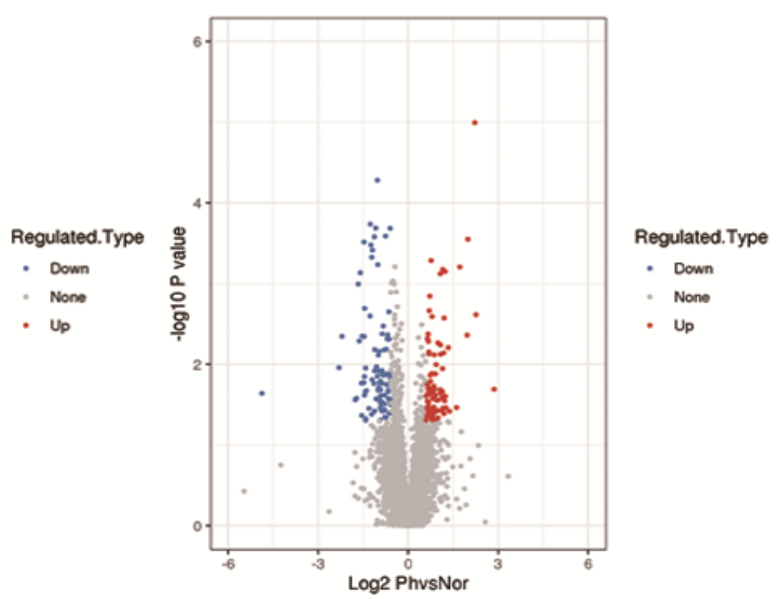

Figure 3

DEPs distribution in different comparative analysis groups between Inter vs. Nor, Ph vs. Nor and Inter vs. Ph. (A) The DEPs distribution of each group is presented by bar chart. (B) A Venn diagram showing the distribution of DEPs. (C) DEPs distribution exhibits by volcano plots, which had fold change $>1.5$ or $<1 / 1.5$ and $p<0.05$. 


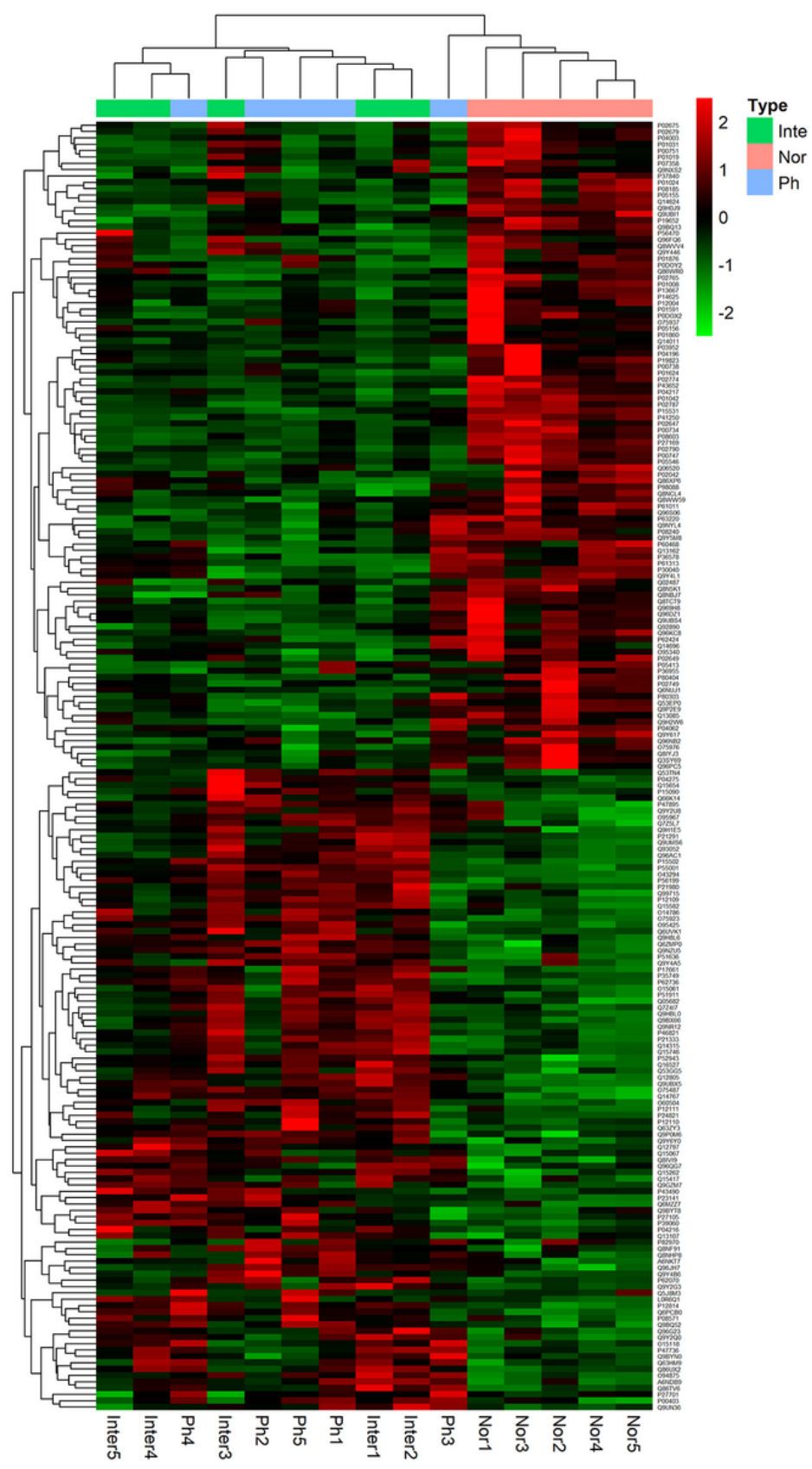

Figure 4

Heatmap and cluster analysis of 423 DEPs in Inter vs. Nor, Ph vs. Nor and Inter vs. Ph. Each line in the heatmap represents the mean fold-change of up-regulation (red) or down-regulation (green) of a protein's expression levels. 


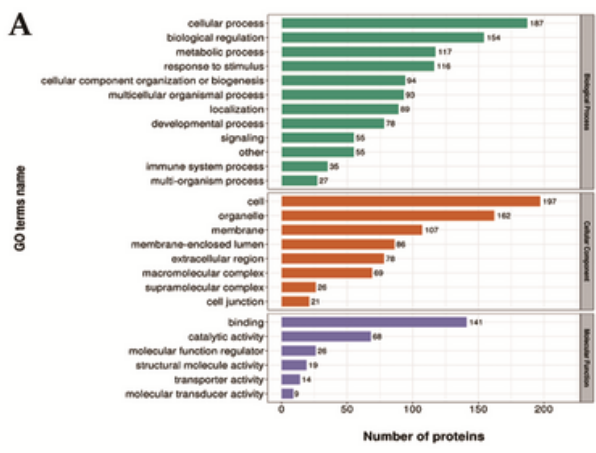

Inter vs. Nor

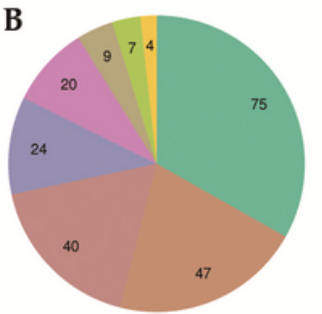

extracellular $(33.19 \%)$ nucleus $(20.8 \%)$

plasma membrane $(10.62 \%)$

mitochondria $(8.85 \%)$

endoplasmic reticulum $(3.98 \%)$

cytoplasm,nucleus $(3.1 \%)$

other $(1.77 \%)$

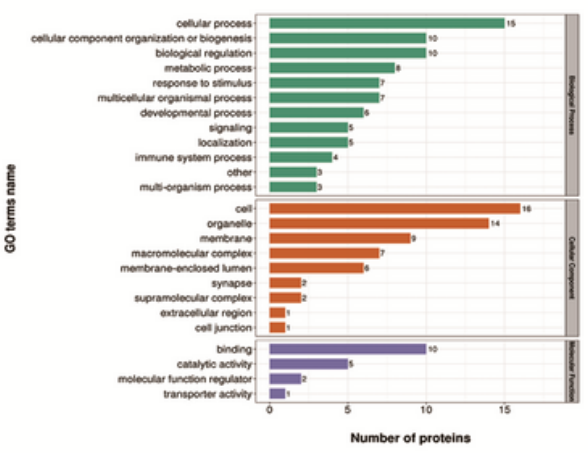

Inter vs. Ph

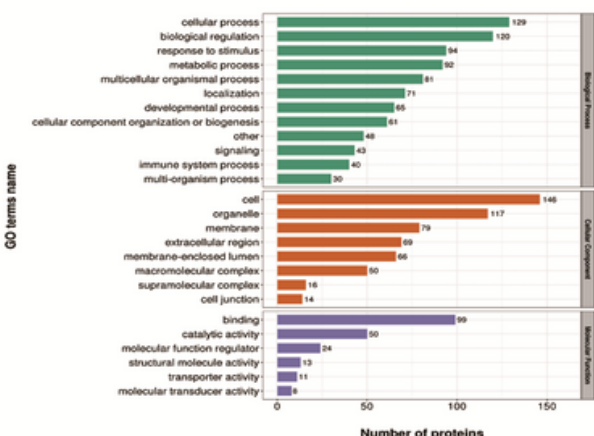

Ph vs. Nor

Inter vs. Nor

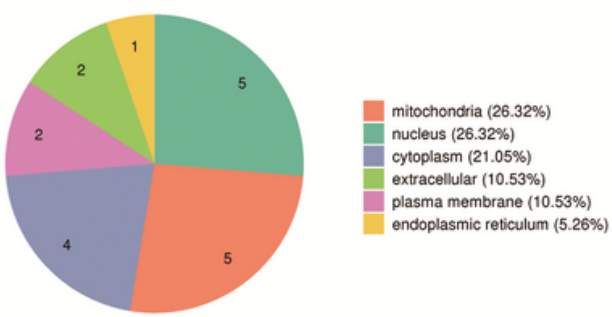

Inter vs. Ph

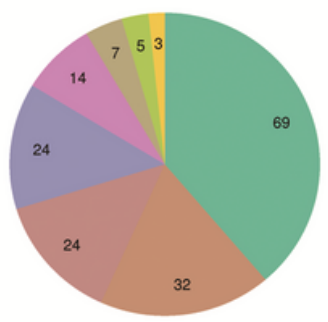

extracellular (38.76\%) nucleus $(17.98 \%)$ cytoplasm (13.48\%) plasma membrane (13.48\%) mitochondria $(7.87 \%)$ endoplasmic reticulum $(3.93 \%)$ cytoplasm,nucleus $(2.81 \%)$ other $(1.69 \%)$

\section{Figure 5}

Gene Ontology (GO) level 2 analysis and subcellular location of DEPs. (A) Functional classification of DEPs for relevant biological processes, molecular functions, and cellular components. (B) Subcellular location of DEPS.

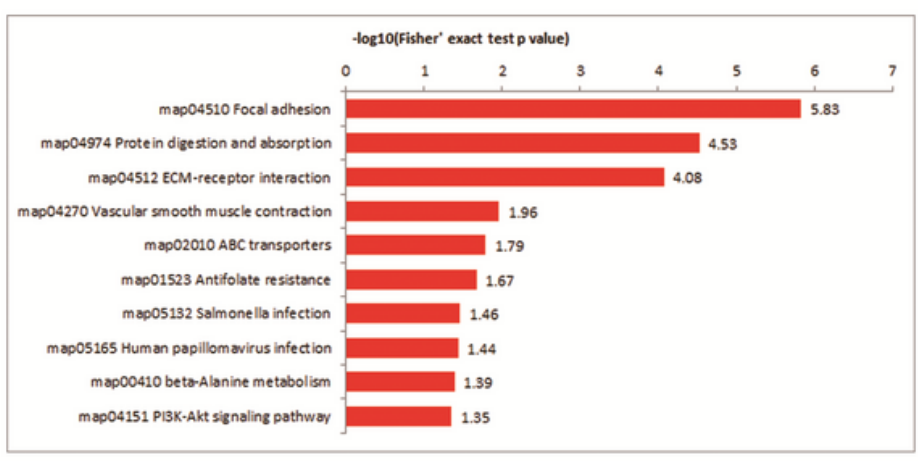

Inter vs. Nor

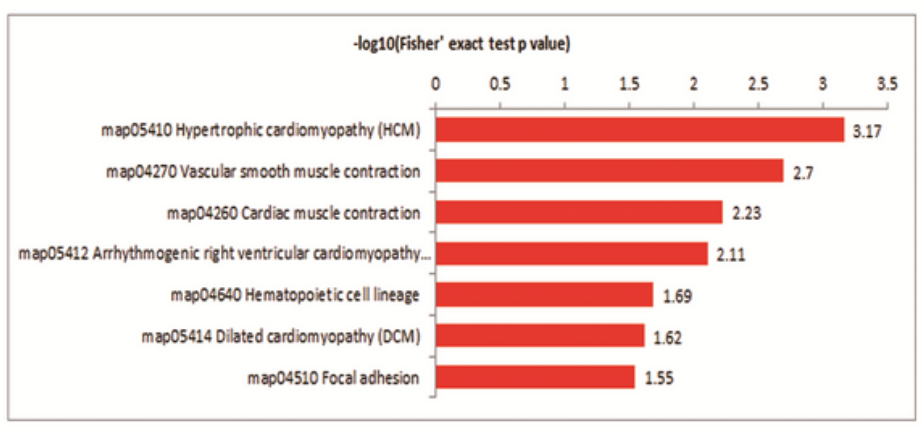

Ph vs. Nor

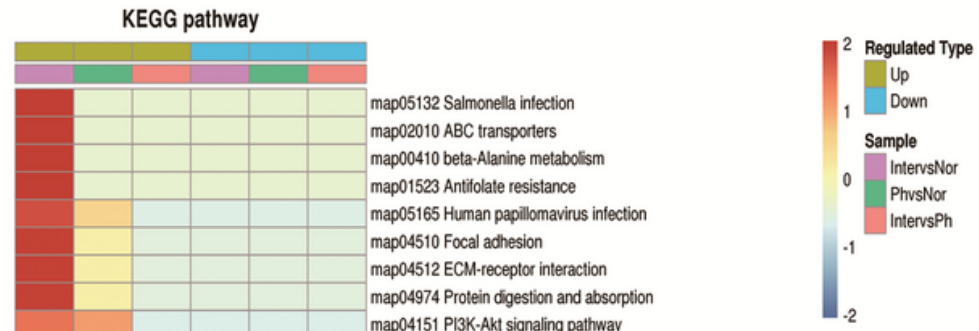

map04151 PI3K-Akt signaling pathway

map04270 Vascular smooth muscle contraction

map04640 Hematopoietic cell Ineage

map05414 Dilated cardiomyopathy (DCM)

map05410 Hypertrophic cardiomyopathy (HCM)

map04260 Cardiac muscle contraction

map05412 Arrhythmogenic right ventricular cardiomyopathy (ARVC)

map05340 Primary immunodeficiency

map03060 Protein export

map05310 Asthma

map04672 Intestinal immune network for lgA production

map04141 Protein processing in endoplasmic reticulum

map04664 Fc epsilon RI signaling pathway

map05140 Leishmaniasis

map05143 African trypanosomiasis

map04610 Complement and coagulation cascades

map05020 Prion diseases

map05322 Systemic lupus erythematosus

map05133 Pertussis

map05150 Staphylococcus aureus infection map04080 Neuroactive ligand-receptor interaction

map00512 Mucin type 0.glycan biosynthesis

map04979 Cholesterol metabolism

map00983 Drug metabolism - other enzymes map00982 Drug metabolism - cylochrome P450

Figure 6

KEGG pathway analysis and heatmap of DEPs in Inter vs. Nor, Ph vs. Nor and Inter vs. Ph. 


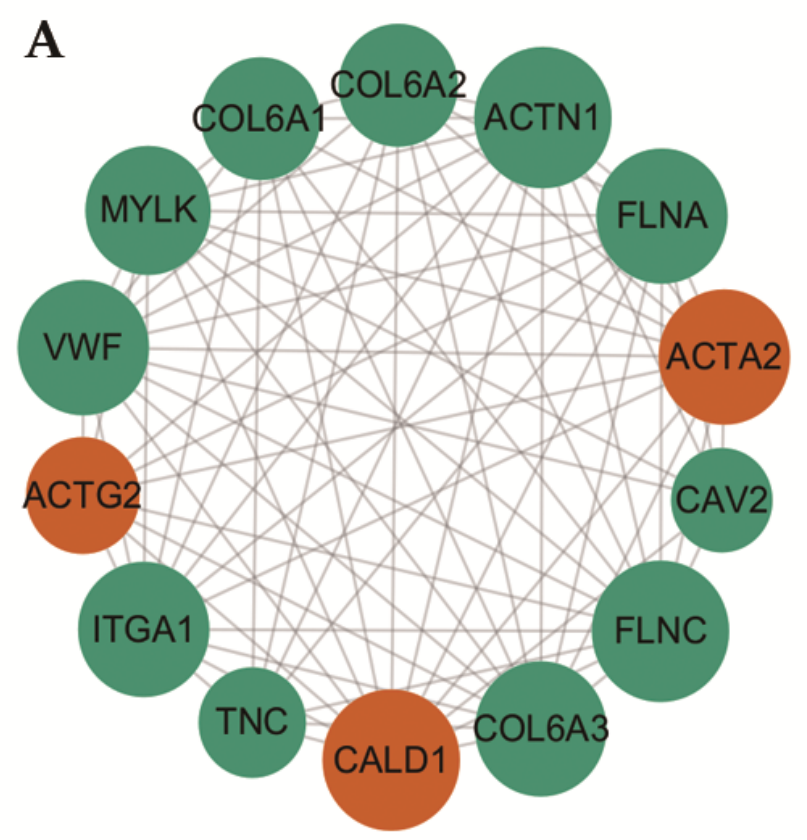

Inter vs. Nor

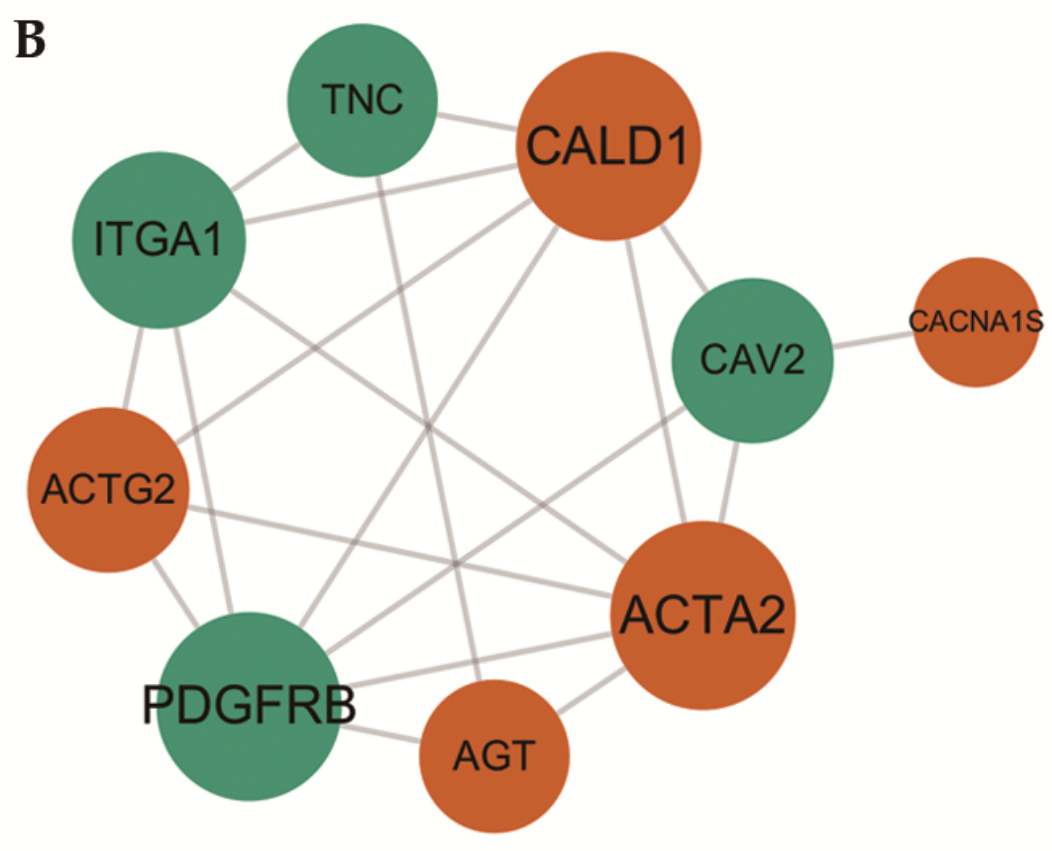

Ph vs. Nor

\section{Focal Adhesion}

\section{Vascular Smooth Muscle Contraction}

Figure 7

STRING Protein-protein interaction (PPI) network of validated interactions between DEPs enriched in focal adhesion and vascular smooth muscle contraction. They were created using STRING v11.0 software together with a 'Homo sapiens' database. 


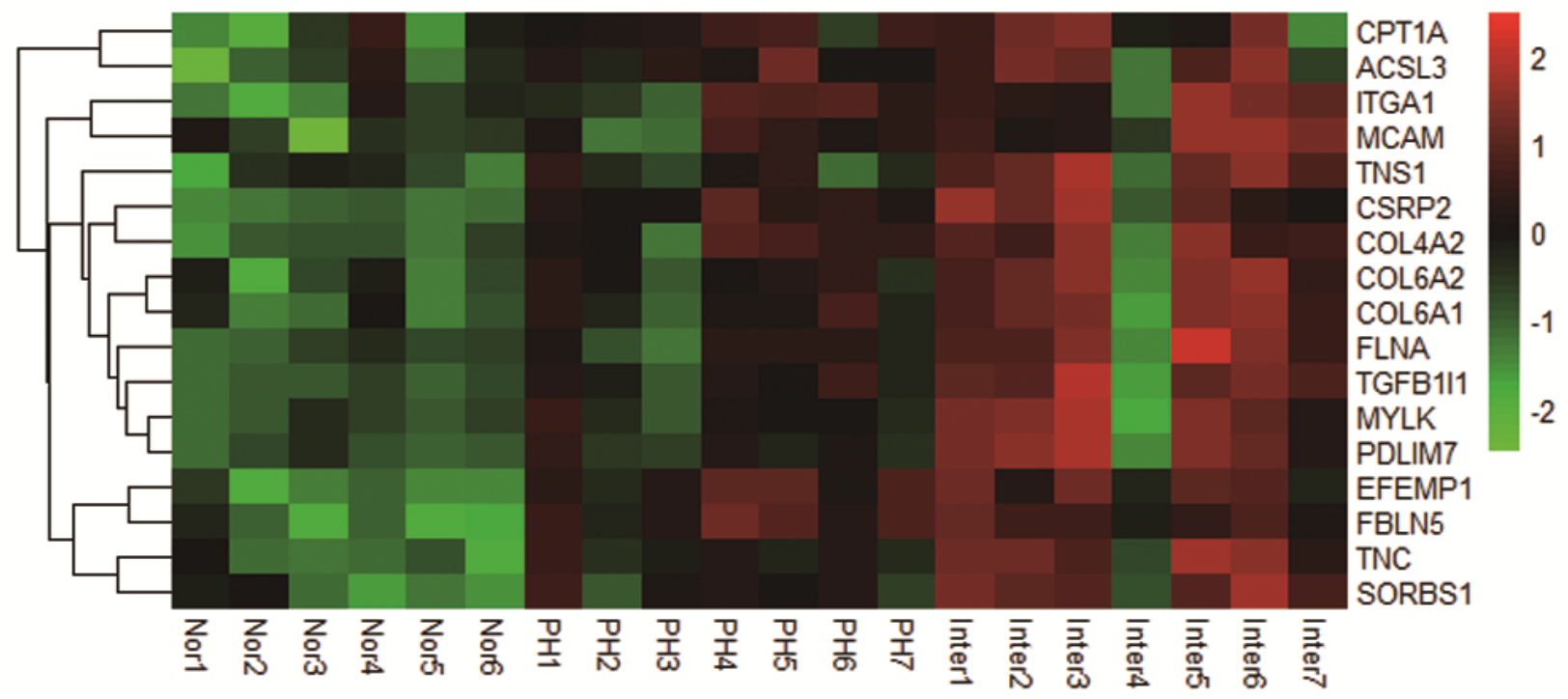

Type 追 Inter 追 Nor 追 PH

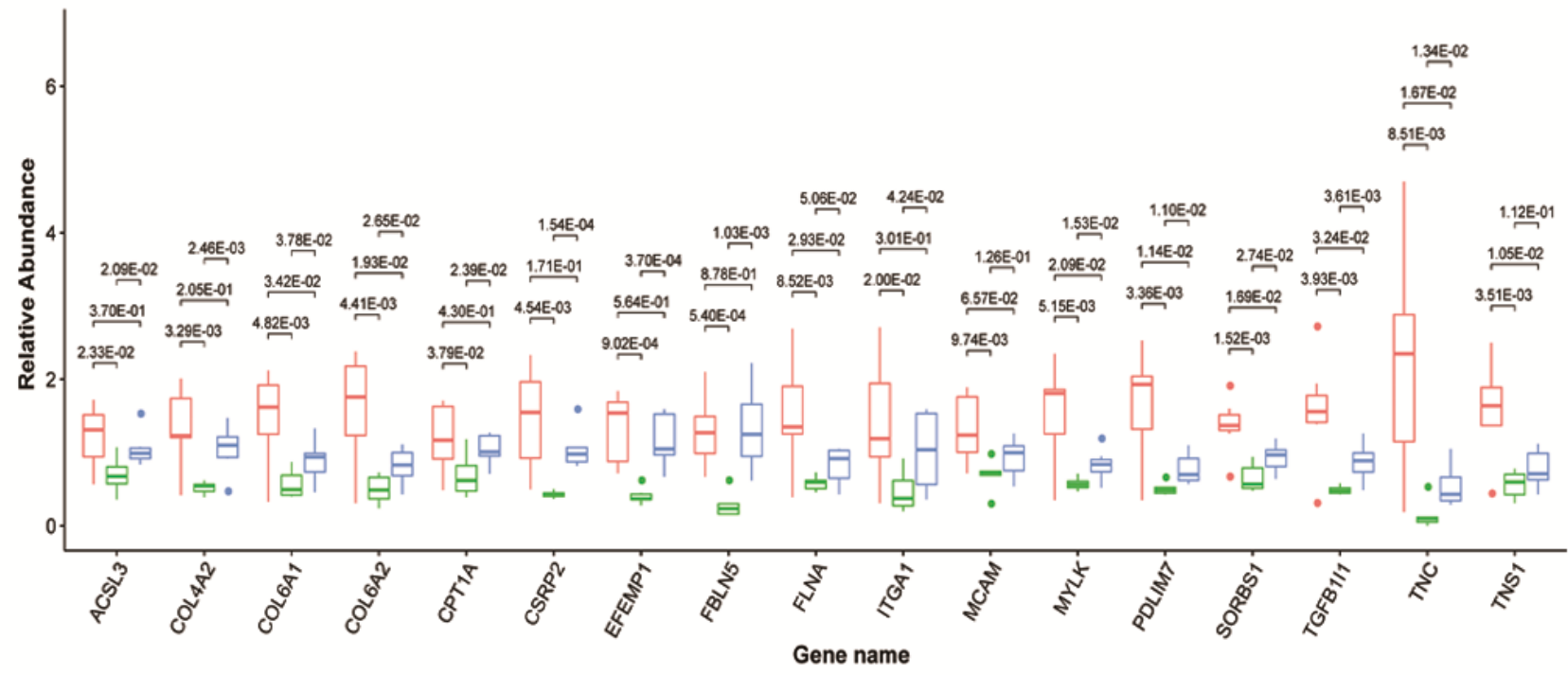

\section{Figure 8}

Heatmap and box plot of 17 DEPs in PHG patients before and after endoscopic cyanoacrylate injection compared with controls by PRM analysis. Each line in the heatmap represents the mean fold-change of upregulation (red) or downregulation (green) of a protein's expression levels. 